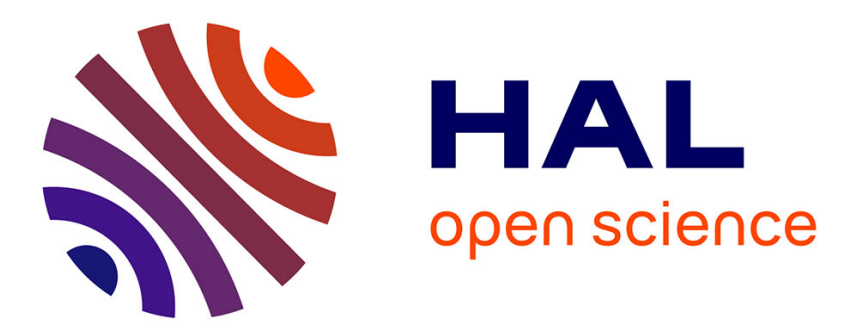

\title{
Magnetic properties of the ternary oxide glasses, Li2O-B2 O3-Fe2O3 from 57Fe Mössbauer spectroscopy
}

\author{
J.P. Sanchez, J.M. Friedt
}

\section{To cite this version:}

J.P. Sanchez, J.M. Friedt. Magnetic properties of the ternary oxide glasses, Li2O-B2 O3Fe2O3 from 57Fe Mössbauer spectroscopy. Journal de Physique, 1982, 43 (11), pp.1707-1716. 10.1051/jphys:0198200430110170700 . jpa-00209553

\section{HAL Id: jpa-00209553 https://hal.science/jpa-00209553}

Submitted on 1 Jan 1982

HAL is a multi-disciplinary open access archive for the deposit and dissemination of scientific research documents, whether they are published or not. The documents may come from teaching and research institutions in France or abroad, or from public or private research centers.
L'archive ouverte pluridisciplinaire HAL, est destinée au dépôt et à la diffusion de documents scientifiques de niveau recherche, publiés ou non, émanant des établissements d'enseignement et de recherche français ou étrangers, des laboratoires publics ou privés. 
Classification

Physics Abstracts

$61.40 \mathrm{D}-75.50 \mathrm{~K}-76.80$

\title{
Magnetic properties of the ternary oxide glasses, $\mathrm{Li}_{2} \mathrm{O}-\mathrm{B}_{2} \mathrm{O}_{3}-\mathrm{Fe}_{2} \mathrm{O}_{3}$ from ${ }^{57}$ Fe Mössbauer spectroscopy
}

\author{
J. P. Sanchez and J. M. Friedt \\ Centre de Recherches Nucléaires, 67037 Strasbourg Cedex, France
}

(Reçu le 13 avril 1982, révisé le 2 juillet, accepté le 22 juillet 1982)

\begin{abstract}
Résumé. - L'état de valence et la coordination du fer ont été établis par spectroscopie Mössbauer de ${ }^{57} \mathrm{Fe}$ dans les oxydes ternaires amorphes, $\mathrm{Li}_{2} \mathrm{O}-\mathrm{B}_{2} \mathrm{O}_{3}-\mathrm{Fe}_{2} \mathrm{O}_{3}$. Dans la gamme de concentrations étudiée $(\leqslant 8,4$ at $\% \mathrm{Fe})$, les ions $\mathrm{Fe}^{3+}$ sont tétra- et hexacoordinés ; la faible proportion $(<15 \%) \mathrm{d}^{3}$ ions $\mathrm{Fe}^{2+}$, observée dans certains échantillons, est liée aux conditions de préparation. Les propriétés magnétiques de ces verres, établies en combinant des mesures macroscopiques (susceptibilité dynamique et aimantation) et locales (spectroscopie Mössbauer), sont déterminées par la concentration des ions fer. A faible concentration $\left(\leqslant 3\right.$ at $\%$ ) de fer, des ions $\mathrm{Fe}^{3+}$ isolés coexistent avec des petits agrégats ( 2 à 3 atomes) antiferromagnétiques. Pour des teneurs en fer plus élevées (3,8 à 8,4 at $\%$ ), les verres présentent une transition mictomagnétique conduisant à un ordre spéromagnétique. Dans un échantillon étudié en détail $(5,8$ at $\% \mathrm{Fe})$, la variation de la température de gel $\left(T_{\mathrm{f}}\right)$ avec la fréquence de mesure obéit à une loi de Fulcher.
\end{abstract}

\begin{abstract}
Fe}$ Mössbauer spectroscopy has been combined with bulk magnetic measurements to determine the valence state and coordination of iron as well as the magnetic properties of the ternary oxide glasses, $\mathrm{Li}_{2} \mathrm{O}-\mathrm{B}_{2} \mathrm{O}_{3}$ $\mathrm{Fe}_{2} \mathrm{O}_{3}$. In all investigated glasses $\left(\leqslant 8.4\right.$ at $\% \mathrm{Fe}$ ), the $\mathrm{Fe}^{3+}$ ions coexist in tetrahedral and octahedral coordinations; the presence of $\mathrm{Fe}^{2+}$ ions $(<15 \%)$, which is observed in some glasses, is related to preparation conditions. The magnetic properties of the glasses are governed by the iron content. At low iron concentration $(<3$ at $\%)$, isolated $\mathrm{Fe}^{3+}$ ions coexist with antiferromagnetic dimers and trimers. At large iron content $(3.8$ to 8.4 at $\%)$ the glasses undergo a mictomagnetic transition to a speromagnetic ordered state. The freezing temperature $\left(T_{\mathrm{f}}\right)$, which is frequency dependent, is found to follow a Fulcher law in one sample (5.8 at \% Fe) investigated in detail.
\end{abstract}

1. Introduction. - Considerable experimental and theoretical work has been devoted recently to the structural $[1,2]$ and magnetic properties $[3,4]$ of disordered systems. The concept of spin glass or mictomagnetism [5], corresponding to the random freezing of spins via a progressive blocking of the magnetization of clusters or via a collective phase transition, has been extended from diluted magnetic alloys (CuMn, AuFe, etc... [6]) to randomly diluted crystalline solids such as $\mathrm{Eu}_{x} \mathrm{Sr}_{1-x} \mathrm{~S}$ [7] or $\mathrm{Eu}_{x} \mathrm{Gd}_{1-x} \mathrm{~S}$ [8] and to amorphous compounds with predominantly antiferromagnetic interactions [9].

The present report concerns the latter class of materials. The properties of the ternary oxide glasses, $\mathrm{Li}_{2} \mathrm{O}-\mathrm{B}_{2} \mathrm{O}_{3}-\mathrm{Fe}_{2} \mathrm{O}_{3}$, are inferred by combining bulk (ac-susceptibility, magnetization) and local $\left({ }^{57} \mathrm{Fe}\right.$ Mössbauer spectroscopy) measurements. In a previous paper on the $\mathrm{BaO}-\mathrm{B}_{2} \mathrm{O}_{3}-\mathrm{Fe}_{2} \mathrm{O}_{3}$ glass systems [10] it has been shown that the magnetic properties are governed by the Fe concentration. Here, more attention is devoted to the dilute concentration range, where isolated $\mathrm{Fe}^{3+}$ ions coexist with small magnetic clusters, and to the intermediate concentration range, where the glasses exhibit a mictomagnetic transition owing to topological disorder and frustration effects. The nature of the transition is investigated in detail for one sample $(5.8$ at $\% \mathrm{Fe})$ by following the dependence of the freezing temperature on the time window $\left(0.5\right.$ to $10^{-8} \mathrm{~s}$ ) of the measuring technique.

2. Experimental. - The amorphous samples were prepared by rapid quenching using the roller technique as described in detail elsewhere [11]. The final compositions of the ternary oxides were checked by standard chemical analysis. The non-crystalline nature of the products was established by X-ray and electron diffraction as well as by transmission electron microscopy. Dc-magnetic data will be reported in 
detail by Chaumont and Bernier in a forthcoming paper [12].

Ac-susceptibility measurements were performed at the C.R.T.B.T. (Grenoble) using a mutual inductance bridge operating between $17 \mathrm{~Hz}$ and $11 \mathrm{kHz}$ [13].

The ${ }^{57} \mathrm{Fe}$ Mössbauer measurements were performed as a function of temperature between 1.4 and $295 \mathrm{~K}$ against a ${ }^{57} \mathrm{Co} / \mathrm{Rh}$ source. Some experiments were carried out in a longitudinal external magnetic field up to $80 \mathrm{kOe}$ provided by a superconducting coil. Absorbers containing about $5 \mathrm{mg} / \mathrm{cm}^{2}$ of natural iron were used. The Mössbauer spectra were computer analysed as described in detail in a preceding paper [10].

3. Experimental results. $-{ }^{57} \mathrm{Fe}$ Mössbauer data are reported for the ternary oxide glasses, $\mathrm{Li}_{2} \mathrm{O}-\mathrm{B}_{2} \mathrm{O}_{3}$ $\mathrm{Fe}_{2} \mathrm{O}_{3}$, of nominal compositions given in table $\mathrm{I}$.

Table I. - Nominal compositions of the ternary oxide glasses, $\mathrm{Li}_{2} \mathrm{O}-\mathrm{B}_{2} \mathrm{O}_{3}-\mathrm{Fe}_{2} \mathrm{O}_{3}$, investigated in this work.

\begin{tabular}{|c|cccc|}
\hline Sample & \multicolumn{3}{|c}{ Molar $\%$} & Atomic \% \\
& $\mathrm{Li}_{2}{ }^{\circ}$ & $\mathrm{B}_{2} \mathrm{O}_{3}$ & $\mathrm{Fe}_{2} \mathrm{O}_{3}$ & $\mathrm{Fe}$ \\
\hline a & 49.5 & 49.3 & 1.2 & 0.6 \\
b & 48.5 & 47.8 & 3.7 & 1.8 \\
d & 47.6 & 46.3 & 6.1 & 3.0 \\
e & 31.7 & 60.0 & 8.3 & 3.8 \\
f & 45.2 & 42.9 & 11.9 & 5.8 \\
B & 30.0 & 53.3 & 16.7 & 6.9 \\
h & 43.0 & 39.5 & 17.5 & 7.6 \\
\hline
\end{tabular}

Complementary ac-susceptibility measurements as a function of temperature and frequency are reported for one specific sample e ( 5.8 at \% Fe), in which the mictomagnetic transition is established in detail.

3.1 MösSBAUER MEASUREMENTS. - At $77 \mathrm{~K}$ the samples $\mathrm{b}, \mathrm{c}$ and $\mathrm{f}$, with respectively $1.8,3.0$ and 6.9

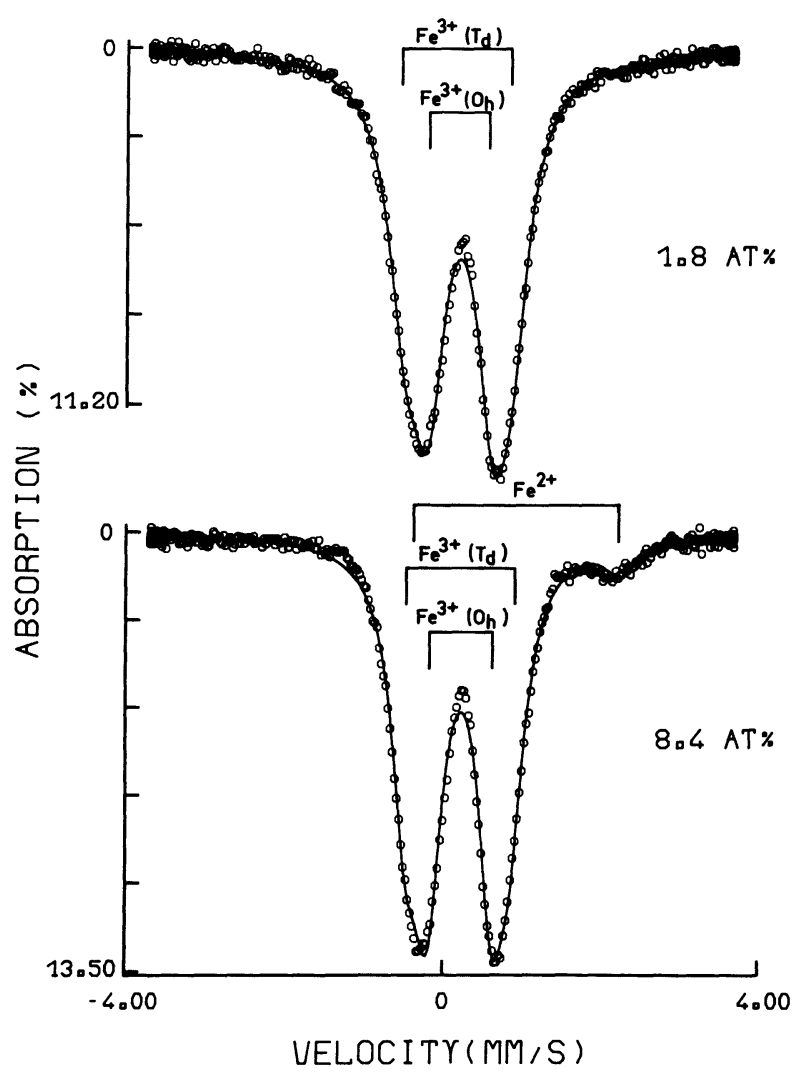

Fig. 1. - Mössbauer spectra of samples b $(1.8$ at $\% \mathrm{Fe})$ and $\mathrm{h}(8.4$ at $\% \mathrm{Fe})$ at $77 \mathrm{~K}$. The full curves correspond to a fit assuming Lorentzian lineshapes (see text).

Table II. - Mössbauer data at $77 \mathrm{~K}$ of the ternary oxide glasses, $\mathrm{Li}_{2} \mathrm{O}-\mathrm{B}_{2} \mathrm{O}_{3}-\mathrm{Fe}_{2} \mathrm{O}_{3}, \delta_{1 \mathrm{~S}}$ is the isomer shift versus iron metal at $R T . \Delta_{\mathrm{L}}$ and $W_{\mathrm{L}}$ represent respectively the quadrupole splitting and the resonance width assuming Lorentzian lineshapes. $P$ is the fractional spectral area of iron in a given coordination and (or) valence state. $x$ is the nominal concentration of $\mathrm{Fe}$ (see Table I).

\begin{tabular}{|c|c|c|c|c|c|c|c|c|c|c|}
\hline \multirow{2}{*}{$\begin{array}{c}x \\
(\text { at } \% \mathrm{Fe})\end{array}$} & \multicolumn{3}{|c|}{$\mathrm{Fe}^{3+}\left(\mathrm{T}_{\mathrm{d}}\right)$} & \multicolumn{3}{|c|}{$\mathrm{Fe}^{3+}\left(0_{h}\right)$} & \multicolumn{3}{|c|}{$\mathrm{Fe}^{2+}$} & \multirow{2}{*}{$\begin{array}{l}\mathrm{W}_{\mathrm{L}}(\mathrm{mm} / \mathrm{s}) \\
\pm 0.02\end{array}$} \\
\hline & $\begin{array}{l}\Delta_{L}(\mathrm{~mm} / \mathrm{s}) \\
\pm 0.02\end{array}$ & $\begin{array}{c}\delta_{\mathrm{IS}}(\mathrm{mm} / \mathrm{s}) \\
\pm 0.02\end{array}$ & $\begin{array}{l}P(\%) \\
\pm 2\end{array}$ & $\begin{array}{c}\Delta_{L}(\mathrm{~mm} / \mathrm{s}) \\
\pm 0.02\end{array}$ & $\begin{array}{c}\delta_{\mathrm{IS}}(\mathrm{mm} / \mathrm{s}) \\
\pm 0.02\end{array}$ & $\begin{array}{l}P(\%) \\
\pm 2\end{array}$ & $\begin{array}{c}\Delta_{L}(\mathrm{~mm} / \mathrm{s}) \\
\pm 0.05\end{array}$ & $\begin{array}{l}\delta_{\text {IS }}(\mathrm{mm} / \mathrm{s}) \\
\pm 0.03\end{array}$ & $\begin{array}{l}P(\%) \\
\pm 3\end{array}$ & \\
\hline 1.8 & 1.34 & 0.40 & 43 & 0.80 & 0.43 & 57 & - & - & 0 & 0.51 \\
\hline 3.0 & 1.32 & 0.40 & 43 & 0.79 & 0.43 & 57 & - & - & 0 & 0.46 \\
\hline 3.8 & 1.38 & 0.45 & 36 & 0.88 & 0.45 & 50 & 2.86 & 1.06 & 14 & 0.47 \\
\hline 5.8 & 1.33 & 0.41 & 41 & 0.80 & 0.44 & 55 & 2.60 & 1.16 & 4 & 0.44 \\
\hline 6.9 & 1.33 & 0.41 & 43 & 0.80 & 0.43 & 57 & - & - & 0 & 0.44 \\
\hline 7.6 & 1.40 & 0.44 & 41 & 0.88 & 0.44 & 54 & 2.96 & 1.02 & 5 & 0.44 \\
\hline 8.4 & 1.32 & 0.41 & 39 & 0.80 & 0.44 & 55 & 2.55 & 1.14 & 6 & 0.44 \\
\hline
\end{tabular}


at $\% \mathrm{Fe}$, present two slightly asymmetric Mössbauer lines (Fig. 1). Assuming Lorentzian lineshapes, the spectra are satisfactorily analysed as a superposition of two broadened quadrupole doublets with different isomer shifts and quadrupole splittings characterizing $\mathrm{Fe}^{3+}$ ions in both octahedral $\left(\mathrm{O}_{h}\right)$ and tetrahedral $\left(\mathrm{T}_{\mathrm{d}}\right)$ coordinations (Table II).

By contrast, the Mössbauer spectra of samples d, e, $\mathrm{g}$ and $\mathrm{h}$ with respectively $3.8,5.8,7.6$ and 8.4 at $\% \mathrm{Fe}$ present at $77 \mathrm{~K}$ a third resonance line at about $2.1 \mathrm{~mm} / \mathrm{s}$ superposed upon the previous two main resonances (Fig. 1). The spectra are decomposed into three symmetrical broadened doublets, indicating the presence of $\mathrm{Fe}^{3+}$ ions, both octahedrally and tetrahedrally coordinated, and of a small amount of $\mathrm{Fe}^{2+}$ ions (Fig. 1, Table II). The observation of $\mathrm{Fe}^{2+}$ ions in these glasses is related to preparation conditions rather than to compositional or other effects.

The Mössbauer spectrum of sample a $(0.6$ at $\% \mathrm{Fe})$ reveals at $77 \mathrm{~K}$ (Fig. 2) a superposition of a central doublet and of a magnetic hyperfine structure (see below).

At $4.2 \mathrm{~K}$, except for sample c $(3.0$ at $\% \mathrm{Fe})$, the Mössbauer spectra of all samples under study reveal a fraction of the iron ions experiencing a magnetic hyperfine field. However, two classes of behaviour

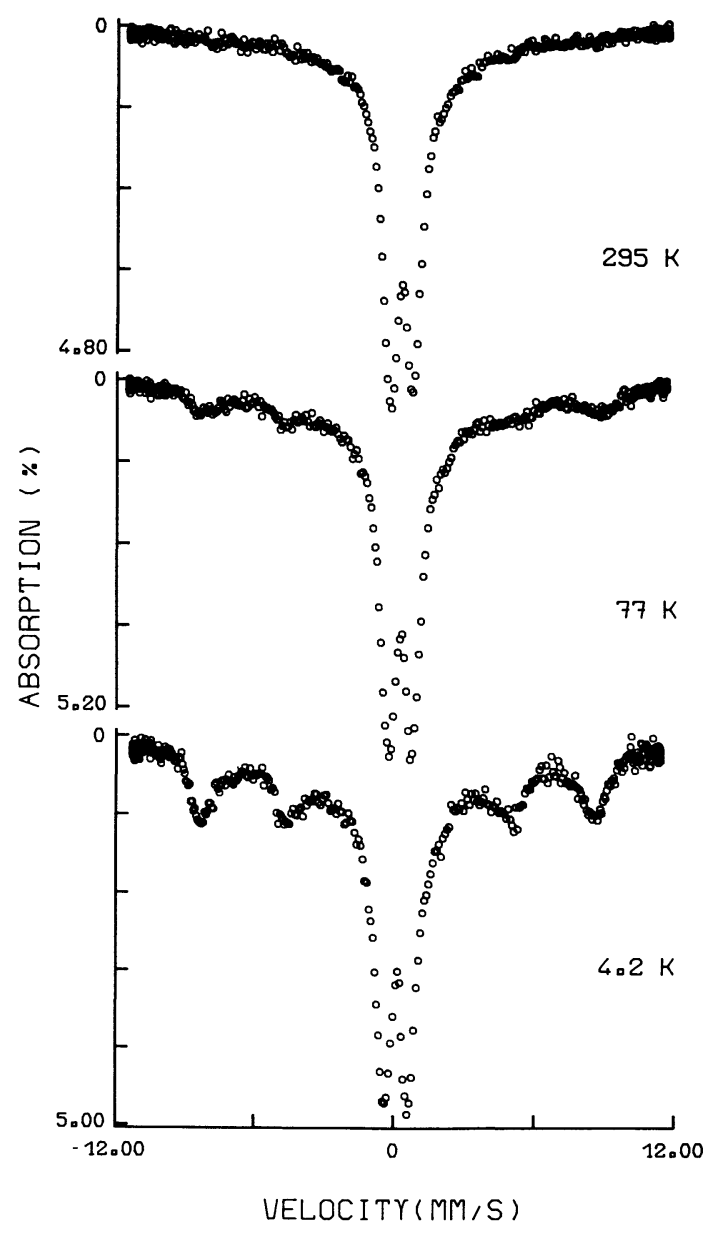

Fig. 2. - Temperature dependence of the Mössbauer spectra of sample a $(0.6$ at $\% \mathrm{Fe})$.

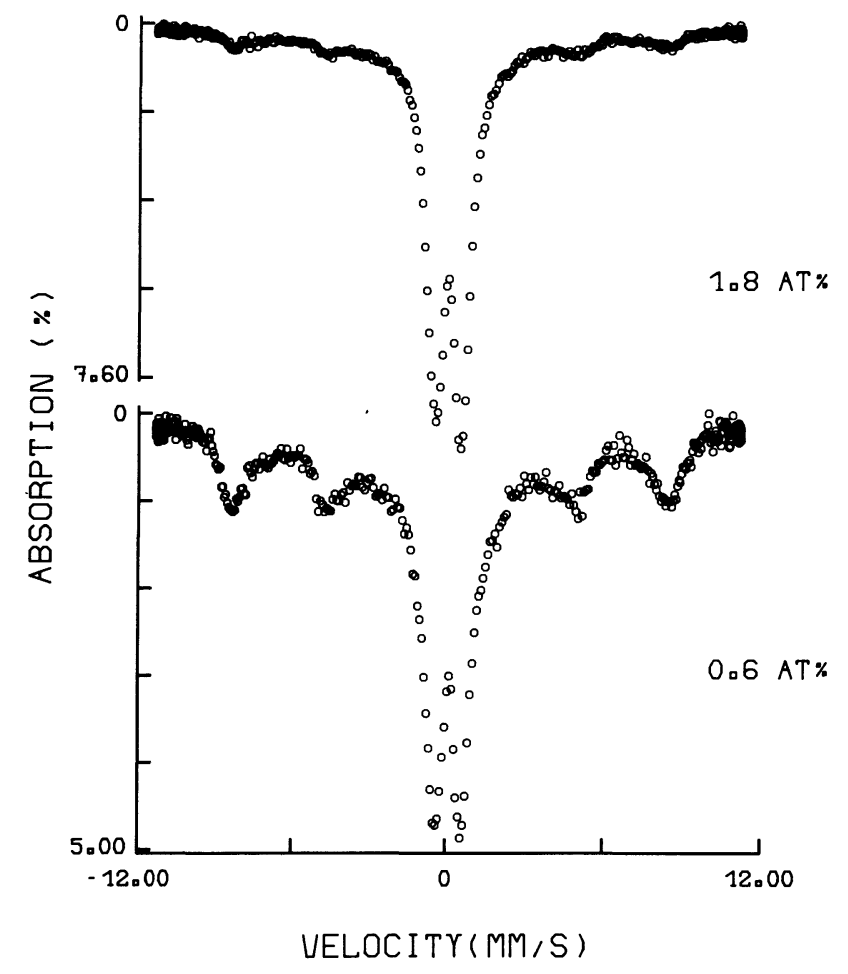

Fig. 3. $-4.2 \mathrm{~K}$ Mössbauer spectra of $\mathrm{Li}_{2} \mathrm{O}-\mathrm{B}_{2} \mathrm{O}_{3}-\mathrm{Fe}_{2} \mathrm{O}_{3}$ glasses at different iron concentrations (lower concentration range, samples $a, b)$.

can be distinguished, according to the iron concentration range. At iron content $x<3.0$ at $\%$, the fraction of iron ions showing a magnetic hyperfine structure decreases with increasing iron concentration; the opposite trend is observed for $x>3.0$ at $\%$ (Figs. 3 and 4).

The former behaviour is characteristic for paramagnetic relaxation effects. In addition to the above mentioned concentration dependence, this attribution is further supported from the temperature dependence of the spectra, which reveal a progressive broadening and collapse of the "magnetic» lines (see Fig. 2 at 77 and $295 \mathrm{~K}$ ). The concentration and temperature dependences correspond to spinspin and spin-lattice coupling relaxation mechanisms respectively. By reference to computed relaxation line shapes, the temperature dependence (Fig. 2) actually indicates a distribution of relaxation rates, which is probably connected to inhomogeneity of the magnetic environment of the $\mathrm{Fe}^{3+}$ ions, as already inferred from the quadrupole interaction distribution. Microcrystalline heterogeneities (e.g. precipitated ferrites etc) in the proportion which would be indicated by the Mössbauer data are ruled out from electron microscopy and bulk magnetization results.

In the larger $\mathrm{Fe}$ concentration range $(x>3.0$ at $\%$, the iron concentration dependence of the 4.2 K Mössbauer spectra (Fig. 4) shows an increase in resolution of the magnetic hyperfine structure with increasing $x$. Detailed temperature dependence study of the spectral shape of sample e (5.8 at \%) 

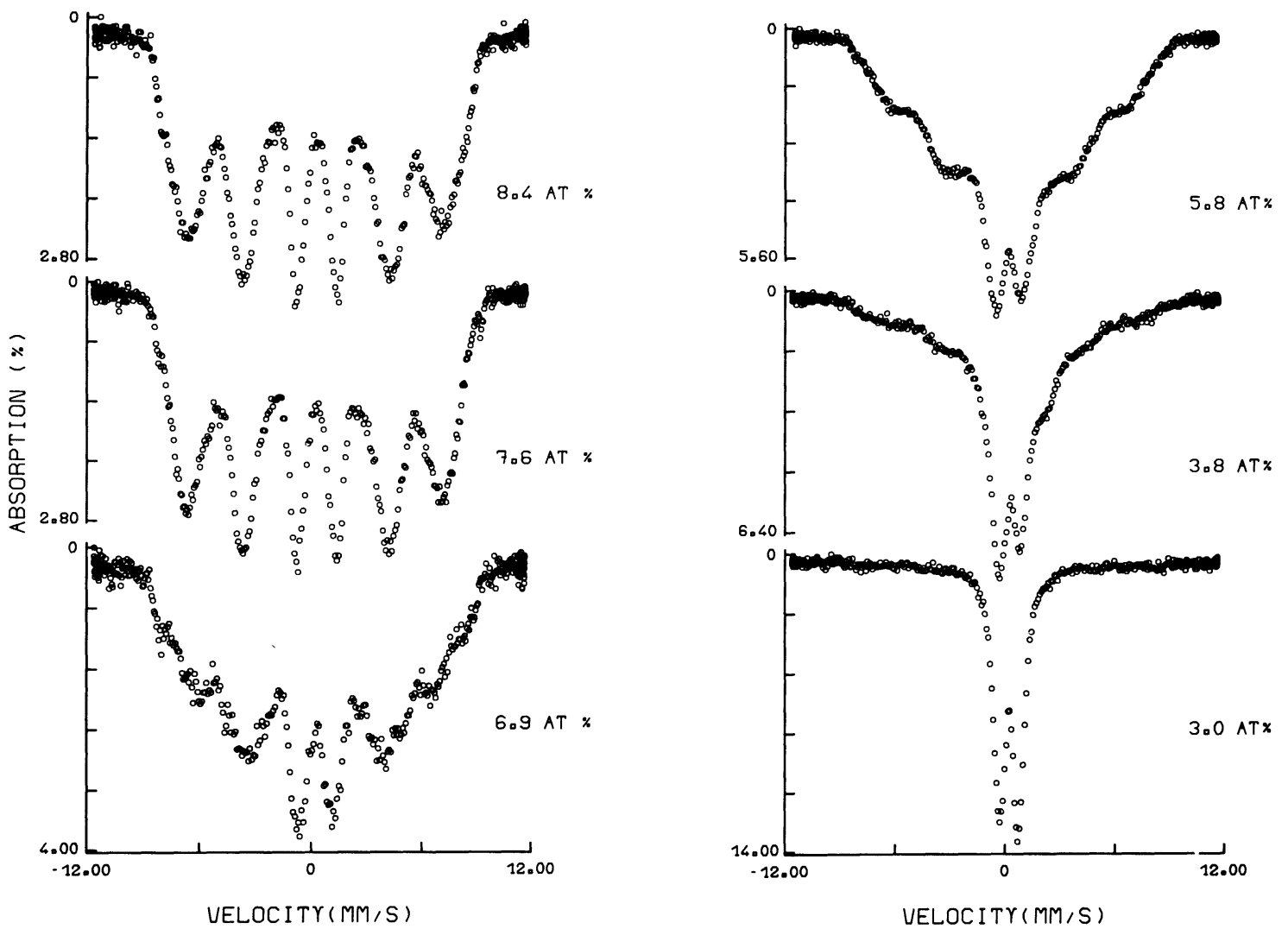

Fig. 4. - 4.2 $\mathrm{K}$ Mössbauer spectra of $\mathrm{Li}_{2} \mathrm{O}-\mathrm{B}_{2} \mathrm{O}_{3}-\mathrm{Fe}_{2} \mathrm{O}_{3}$ glasses at different iron concentrations (upper concentration range, samples $\mathrm{c}$ to $\mathrm{h}$ ).

indicates that the magnetic hyperfine structure sets in at $7 \pm 0.5 \mathrm{~K}$ (Fig. 5). The magnetic hyperfine splitting increases and the lines become less broadened when the temperature decreases. Magnetic saturation is achieved at $1.4 \mathrm{~K}$ only for the more concentrated sample $\mathrm{h}(8.4$ at $\%)$ for which magnetic broadening occurs at $14 \pm 2 \mathrm{~K}$.

For this sample $h(8.4$ at $\% \mathrm{Fe})$, the saturated magnetic spectrum $(1.4 \mathrm{~K})$ is analysed in the hypothesis of an "amorphous" magnetic structure, using a fitting procedure described in detail in [10] (Fig. 6) : a random orientation is assumed for the angle $\theta$ between electric field gradient and hyperfine field principal axes. This results, to first order, in a symmetrical magnetic spectrum. The effects of the above angular distribution and of the distribution of quadrupole splitting are represented by a uniform broadening of all the magnetic components given from a perturbation calculation as $[10,14]$ :

$$
W=\left(W_{\mathrm{L}}^{2}+W_{\theta}^{2}\right)^{1 / 2}
$$

where $W_{\mathrm{L}}$ is the linewidth observed in the paramagnetic state $(77 \mathrm{~K})$ and $\delta W_{\theta}=\frac{1}{\sqrt{5}} \Delta$, with $\Delta$ being the quadrupole splitting deduced from the paramagnetic data. The distribution function of the hyperfine field is then fitted directly from the data.
The average fields and the standard deviations for both the octahedrally and tetrahedrally coordinated $\mathrm{Fe}^{3+}$ ions are collected in table III. It should be noticed that the average hyperfine fields,

$$
\mathrm{Fe}^{3+}\left(\mathrm{O}_{\mathrm{h}}\right)=467 \mathrm{kOe}, \mathrm{Fe}^{3+}\left(\mathrm{T}_{\mathrm{d}}\right)=402 \mathrm{kOe},
$$

are lower than those measured in crystalline iron-based oxides (e.g. $\mathrm{Fe}^{3+}\left(\mathrm{O}_{\mathrm{h}}\right)=537.5 \mathrm{kOe}, \mathrm{Fe}^{3+}\left(\mathrm{T}_{\mathrm{d}}\right)=521 \mathrm{kOe}$ in $\mathrm{LiFe}_{5} \mathrm{O}_{8}$ at $\left.4.2 \mathrm{~K}\right)$ or than that $(530 \mathrm{kOe})$ determined for isolated $\mathrm{Fe}^{3+}$ ions under a large external field at $4.2 \mathrm{~K}$ (see below).

3.2 SUSCEPTIBILITY MEASUREMENTS. - Preliminary dc-susceptibility and magnetization measurements have been reported by Chaumont et al. [1.1]. A more detailed account of their work will be published [12]. The main features of their data are summarized here.

Reciprocal susceptibilities, $\chi^{-1}$, of the glasses under study follow a Curie-Weiss law above some characteristic temperature $T_{\mathrm{D}}$ (e.g. $100 \mathrm{~K}$ for sample $\mathrm{h}$ with 8.4 at $\% \mathrm{Fe}$ ) and show a negative curvature below this temperature. The latter feature indicates a change in the system, probably connected with the formation of magnetic cluster [15]. The negative Curie temperatures, $\theta_{\mathrm{p}}$, reveal dominant antiferromagnetic exchange interactions. The molar Curie- 


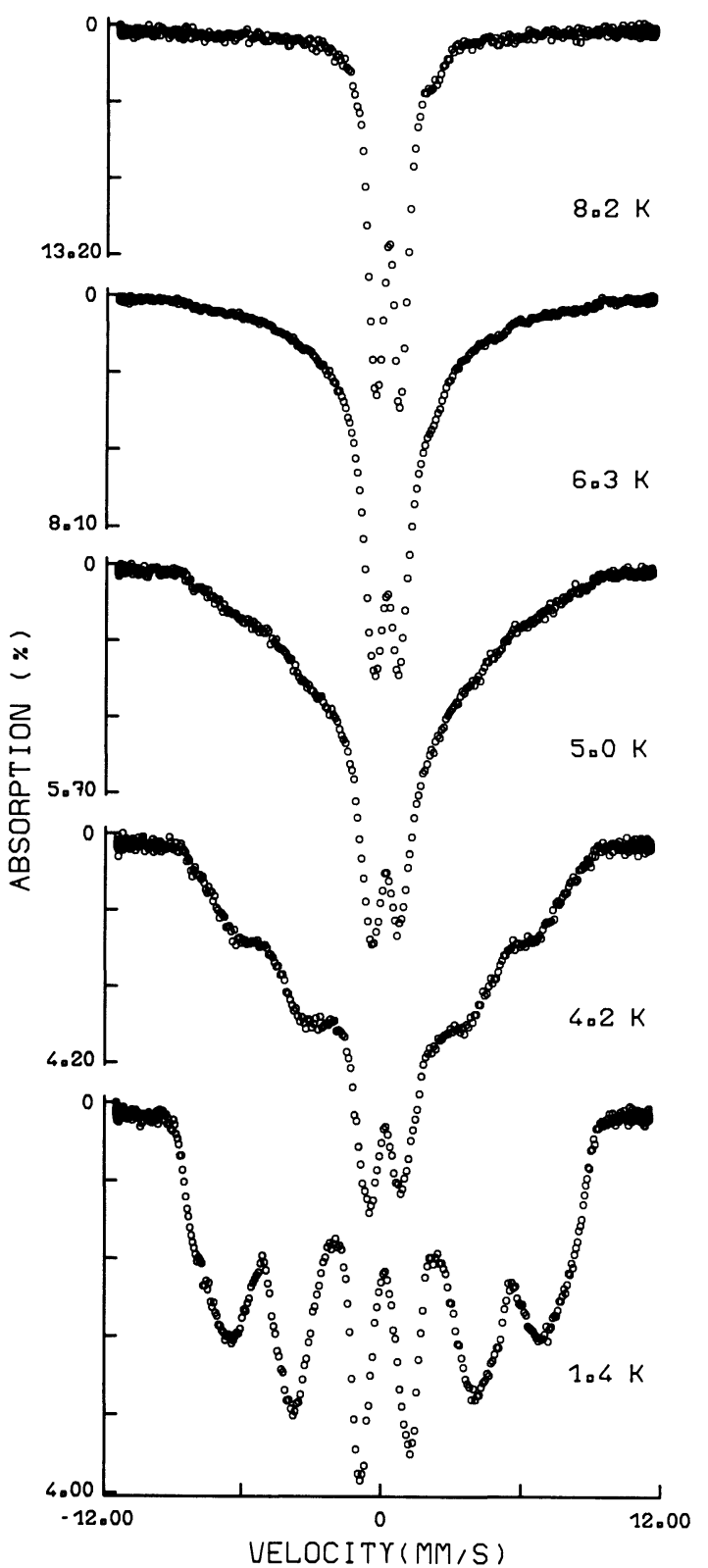

Fig. 5. - Temperature dependence of the Mössbauer spectra of sample e $(5.8$ at $\% \mathrm{Fe})$ around the magnetic transition.

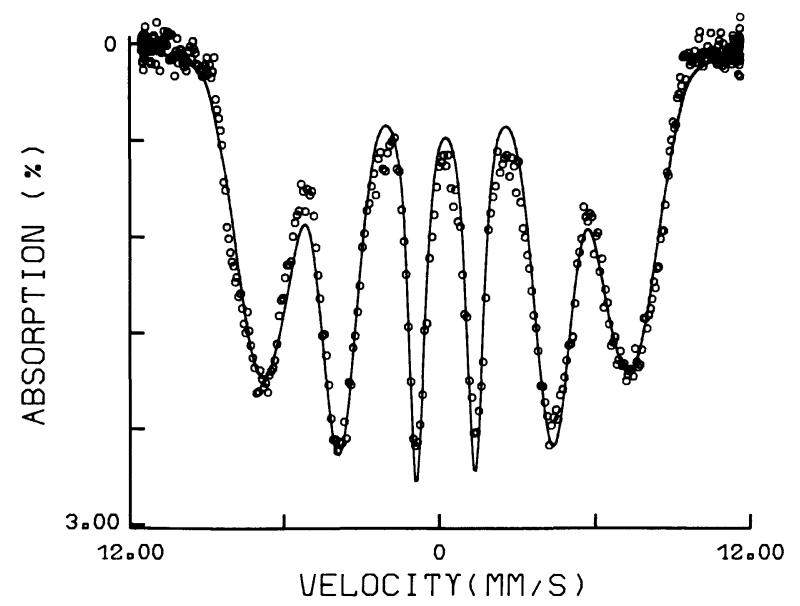

Fig. 6. - Mössbauer spectrum of sample h $(8.4$ at $\% \mathrm{Fe})$ at $1.4 \mathrm{~K}$. The full curve corresponds to a fit as discussed in the text.
Table III. - Hyperfine interaction data from the analysis of the Mössbauer spectrum of sample $\mathrm{h}(8.4$ at $\% \mathrm{Fe}$ ) at $1.4 \mathrm{~K} . \bar{H}_{\mathrm{hf}}$ and $\sigma$ are respectively the mean value and the standard deviation of the Gaussian distribution of the hyperfine field. $\sigma$ is assumed to be the same for the tetrahedral and octahedral hyperfine field distributions. Other symbols are defined as in Table II.

\begin{tabular}{|c|c|c|c|c|c|}
\hline$T(K)$ & & $\begin{array}{c}\delta_{\mathrm{IS}}(\mathrm{mm} / \mathrm{s}) \\
\pm 0.02\end{array}$ & $W^{*}(\mathrm{~mm} / \mathrm{s})$ & $\begin{array}{c}\overline{\mathrm{H}}_{\mathrm{hf}}(\mathrm{k} 0 \mathrm{e}) \\
\pm 5\end{array}$ & $\begin{array}{c}\sigma \\
\pm 0.05\end{array}$ \\
\hline \multirow{2}{*}{1.4} & $\mathrm{Fe}^{3+}\left(\mathrm{T}_{\mathrm{d}}\right)$ & 0.43 & $0.74^{*}$ & 402 & 48.8 \\
& $\mathrm{Fe}^{3+}\left(\mathrm{O}_{\mathrm{h}}\right)$ & 0.46 & $0.57^{*}$ & 467 & \\
\hline
\end{tabular}

* The random orientation of the angle $\theta$ between the EFG and $H_{\mathrm{hf}}$ axes is taken into account by introducing an uniform broadening of the lines and setting the quadrupole splitting $\Delta$ equal to zero (see text).

Weiss constants, $C_{\mathrm{M}}$, are in general significantly lower than the free ion $\mathrm{Fe}^{3+}$ value $\left(C_{\mathrm{t}}=4.38\right)$; they increase with decreasing $\mathrm{Fe}$ concentration, reaching $C_{\mathrm{t}}$ for the less concentrated samples $(\leqslant 0.6$ at $\% \mathrm{Fe})$. The modulus of $\theta_{\mathrm{p}}$ decreases (from $115 \mathrm{~K}$ to zero) with decreasing iron content. In none of the samples does $\chi^{-1}$ show a minimum; absence of remanence effects is observed within the investigated temperature range, i.e. above $4.2 \mathrm{~K}$.

Magnetization (per at $\mathrm{g} \mathrm{Fe}$ ) decreases with increasing iron content and does not saturate even for the less-concentrated iron sample (up to $150 \mathrm{kOe}$ at $4.2 \mathrm{~K})$. For instance, for sample e $(5.8$ at $\%)$ the magnetization at $4.2 \mathrm{~K}(20 \mathrm{kOe})$, which amounts to $2100 \mathrm{emu} /$ at $\mathrm{g} \mathrm{Fe}$, is far below the $\mathrm{Fe}^{3+}$ free-ion saturation value of $27924 \mathrm{emu} / \mathrm{at} \mathrm{g} \mathrm{Fe}$. At $4.2 \mathrm{~K}$, the $M(H)$ curve of this same sample (e) shows a slight curvature except in the low field region $(<5 \mathrm{kOe})$ where a very weak ferrimagnetic component $\left(\mathrm{LiFe}_{5} \mathrm{O}_{8}\right.$ crystallites) saturates. The shape is similar to those found in amorphous manganese aluminosilicates [16].

The ac-susceptibility of sample e (5.8 at \%) exhibits a somewhat broad cusp below $4.2 \mathrm{~K}$ which is frequency dependent; it takes place at temperatures of $3.25,3.35$ and $3.45 \mathrm{~K}$ for respective measuring frequencies of 17.3, 197.6 and $2103 \mathrm{~Hz}$ (Fig. 7). This cusp defines the spin freezing temperature $T_{\mathrm{f}}$. In the frequency range accessible to ac-susceptibility $T_{\mathrm{f}}$ varies linearly with $\log v$; the slope of the relative shift of $T_{\mathrm{f}}$ against decimal logarithm of frequency,

$$
\Delta T_{\mathrm{f}} /\left(T_{\mathrm{f}} \cdot \Delta \log v\right) \simeq 0.03,
$$

is an order of magnitude larger than in the canonical metallic spin glass CuMn [17]. Note that the assumption of an Arrhenius law for the frequency dependence of $T_{\mathrm{f}}\left(T_{\mathrm{f}}^{-1}=-\frac{k}{E_{\mathrm{a}}} \ln \frac{v}{v_{0}}\right)$ leads to unphysical values 


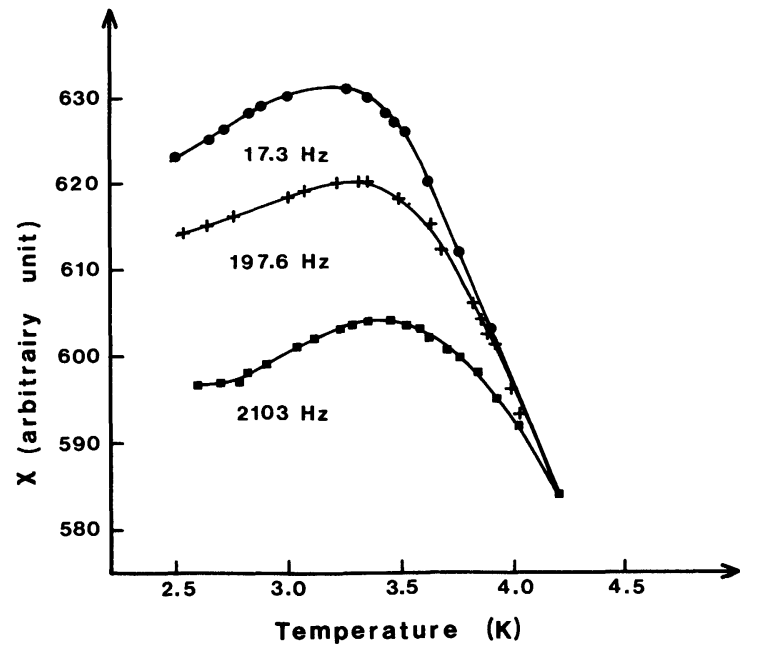

Fig. 7. - Ac-susceptibility of sample e $(5.8$ at $\% \mathrm{Fe})$ as a function of temperature for various measuring frequencies.

for both the characteristic frequency

$$
\left(v_{0} \simeq 8 \times 10^{36} \mathrm{~Hz}\right)
$$

and the activation energy $\left(E_{\mathrm{a}} / k \simeq 270 \mathrm{~K}\right)$.

4. Magnetic properties of the ternary oxide glasses : $\mathrm{Li}_{2} \mathbf{O}-\mathrm{B}_{2} \mathrm{O}_{3}-\mathrm{Fe}_{2} \mathrm{O}_{3}$. - Combining the present Mössbauer and ac-susceptibility data with results from dcsusceptibility and magnetization measurements [11, 12], it appears that the investigated iron-based oxide glasses exhibit two distinct classes of magnetic behaviour, according to the concentration range of the magnetic iron ions. The boundary between the two regimes lies in the range 3.0-3.8 at \% Fe.

4.1 UPPER CONCENTRATION RANGE. - Consider first sample e $(5.8$ at $\% \mathrm{Fe})$ which is representative of this concentration range. Above $7 \pm 0.5 \mathrm{~K}$, the Mössbauer spectra present quadrupole doublets revealing " paramagnetic " behaviour (Fig. 5). Below $7 \mathrm{~K}$ the doublet smears out and develops progressively into a magnetic lineshape (Fig. 5). In the presence of an intense external field ( 40 and $80 \mathrm{kOe}$ ) at $4.2 \mathrm{~K}$, the spectral resolution is significantly enhanced and the spectral splitting increases (Fig. 8).

Several explanations may be considered in order to account for this behaviour. Superparamagnetic effects can hardly be invoked; indeed, neither electron microscopy nor magnetization data indicate the presence of superparamagnetic particles. Moreover, the Mössbauer spectra do not present the temperature dependence characteristic for superparamagnets i.e. a fully developed magnetic spectrum coexisting with a paramagnetic doublet over a wide temperature range [18]. Also, magnetic field saturation, which should be easily achieved for small independent magnetic particles even in a relatively small external field, is not observed.

Paramagnetic relaxation effects, corresponding to

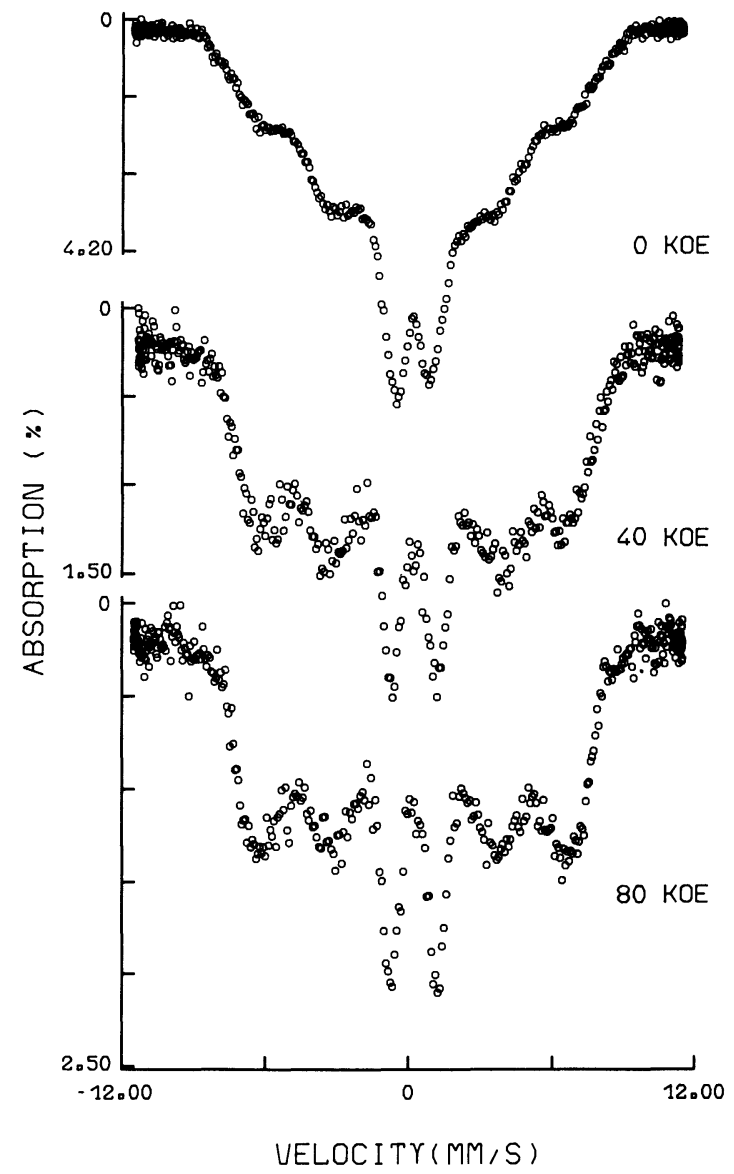

Fig. 8. - Applied field dependence of the Mössbauer spectra of sample e $(5.8$ at $\% \mathrm{Fe})$ at $4.2 \mathrm{~K}$ (external field parallel to $\gamma$-ray propagation axis).

spin flipping of individual $\mathrm{Fe}^{3+}$ ions, are reasonably ruled out from the relative narrowness of the temperature range where these effects would occur (compare figures 2 and 5) and from the temperature dependence of the spectral shape (by reference to established examples and calculations).

The observed temperature and external field dependences of the Mössbauer spectra of sample e, along with the ac-susceptibility cusp, rather suggest a mictomagnetic transition [5]. Over a temperature range below $T_{\mathrm{f}}$, the Mössbauer spectral shapes can be reproduced qualitatively by a spherical relaxation model $[8,19,20]$, when assuming some distribution of relaxation rate. This latter assumption is necessary in particular to represent the apparent persistence of the paramagnetic doublet, while a unique isotropic relaxation rate would imply a fast smearing out of these peaks $[8,19,20]$. The alternative explanation of temperature dependent exchange field distribution cannot be definitively ruled out from the present results. Notice that the proposed interpretation is consistent with the one demonstrated in another established concentrated spin glass system, i.e. ${E u_{1-x}} \mathrm{Gd}_{x} \mathrm{~S}$, where a narrow frequency distribution allows the data to be represented [8]. 
The mictomagnetic transition is understood in terms of a progressive freezing of the isotropic fluctuations of magnetization of clusters $[5,8,21]$. Contrary to the original model of Tholence and Tournier [21], which assumed the existence of essentially independent magnetic clouds (clusters), the external field dependence of the Mössbauer spectra indicates strong interactions among the clusters via dipolar and/or exchange interactions. Indeed, very large fields are required to block the relaxation and saturation is not even reached at $80 \mathrm{kOe}$. The same conclusion is ascertained from the frequency dependence of the freezing temperature $T_{\mathrm{f}}[22-25]$. Defining the Mössbauer freezing temperature as the temperature of appearance of the wings coexisting with the quadrupole doublet (Fig. 5), the frequency dependence of $T_{\mathrm{f}}$ can be extended from the $\chi_{\mathrm{ac}}$ range to $10^{8} \mathrm{~Hz}$, i.e. the characteristic frequency of ${ }^{57} \mathrm{Fe}$ Mössbauer spectroscopy. An Arrhénius plot, $T_{\mathrm{f}}^{-1}$ $v s$. $\ln v$, shows a curvature, indicating that such a law cannot represent the frequency dependence. A better description of the frequency dependence of $T_{\mathrm{f}}$ is achieved by using a Fulcher law,

$$
v=v_{0} \exp \left(-\frac{E_{\mathrm{a}}}{k\left(T_{\mathrm{f}}-T_{0}\right)}\right)
$$

where $T_{0}$ is a phenomenological parameter which takes into account the interactions among the clusters [22-25]. The plot of $T_{\mathrm{f}} v$ s. $1 /\left(\ln v-\ln v_{0}\right)$ is linear with a characteristic frequency $v_{0}=10^{9} \mathrm{~Hz}$ (Fig. 9). The interaction energy, $T_{0}$, and the activation energy, $E_{\mathrm{a}} / k$, are 2.7 and $9.9 \mathrm{~K}$ respectively. These values are comparable to those obtained in manganese and cobalt aluminosilicate glasses [23].

At temperatures well below $T_{\mathrm{f}}$ the magnetization fluctuation is frozen, resulting into a static "amorphous" type Mössbauer spectrum as found for sample $\mathrm{h}$ at $1.4 \mathrm{~K}$ (Fig. 6).

In summary, although the dynamics involved at the mictomagnetic transition cannot be elucidated unambiguously from the present results, it is qualitatively argued that freezing takes place at $T_{\mathrm{f}}$ via a

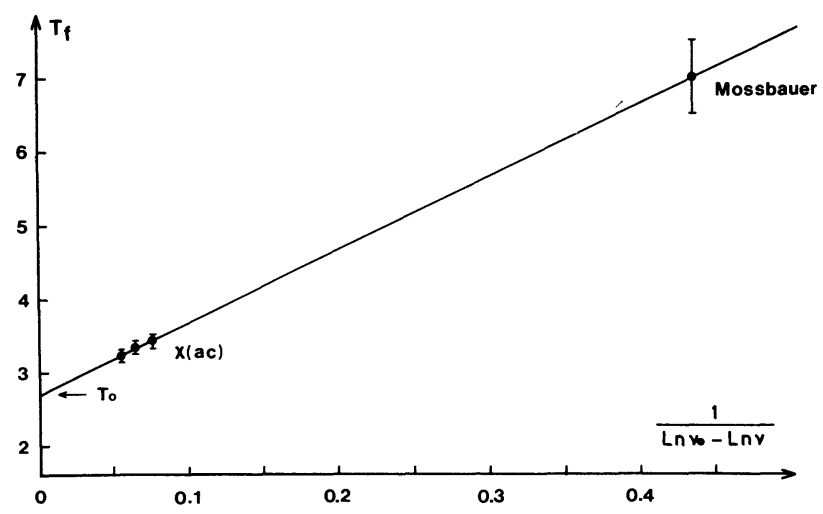

Fig. 9. - Frequency dependence of $T_{\mathrm{f}}$ for sample e (5.8 at $\% \mathrm{Fe}$ ) using a Fulcher law. $T_{0}$ and $E_{\mathrm{a}} / k$ are deduced from the plot of $T_{\mathrm{f}} v s .1 /\left(\ln v_{0}-\ln v\right)$ with $v_{0}=10^{9} \mathrm{~s}^{-1}$. spherical relaxation mechanism. The fluctuations of magnetization of individual clusters are strongly coupled. This is deduced from the frequency dependence of $T_{\mathrm{f}}$ and from the relatively narrow range of relaxation rates. Indeed, in the presence of such interactions between clusters, the relaxation rate will be less dependent on cluster size than for instance in a true superparamagnet.

The temperature dependence of the Mössbauer spectra of the other samples belonging to the large concentration regime ( 3.8 to 8.4 at $\%$ ) has been investigated in less detail. It appears that the freezing temperature is approximately proportional to the iron atomic fraction. The increase of $T_{\mathrm{f}}$ is also evident from the evolution of the spectral shape at $4.2 \mathrm{~K}$ with iron concentration, which reveals an increasing fraction of magnetic component (Fig. 4).

The reduction of saturation hyperfine field in the ordered (speromagnetic) state as compared to the extrapolated paramagnetic value (evaluated from the external field measurements) or to the value in comparable crystalline compounds cannot be attributed to changing covalency effects [26] in view of the similar $\delta_{\text {Is }}$. More reasonably, one may invoke largely different supertransferred and dipolar contributions to the hyperfine field in amorphous materials as a consequence of positional disorder. Alternatively, zero-point spin deviations might be responsible for $H_{\text {hf }}$ and moment reduction [26], as established for

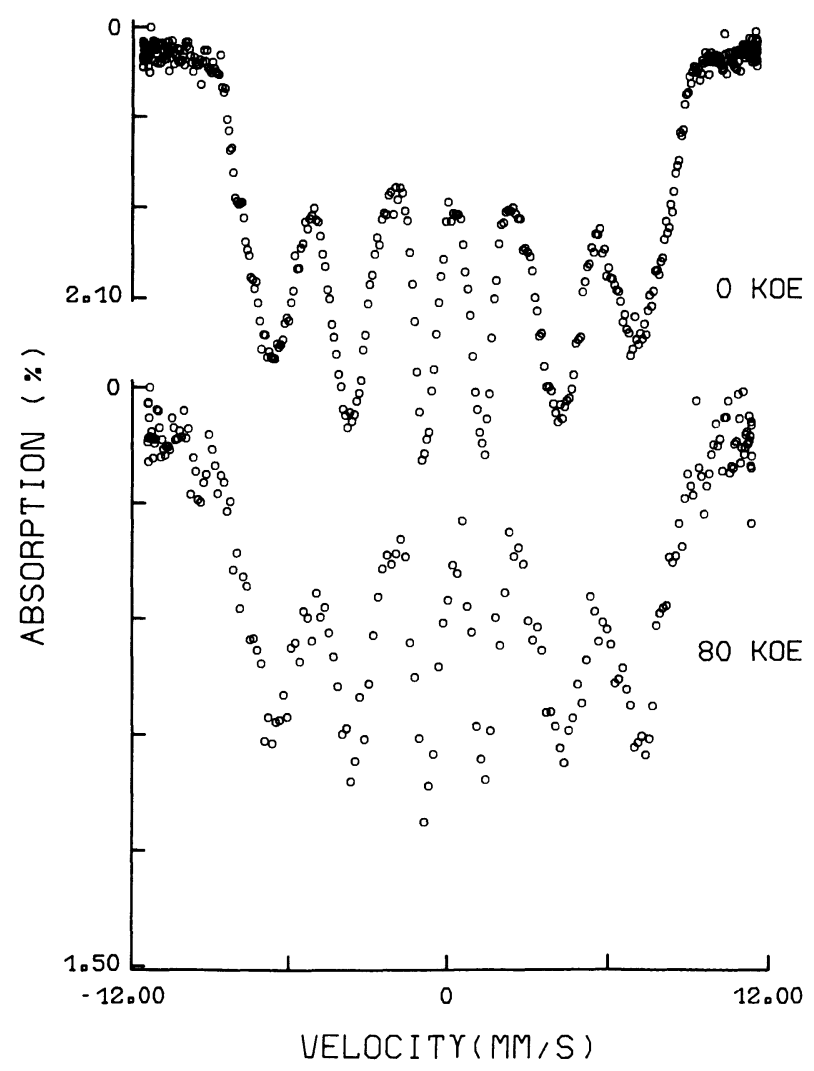

Fig. 10. - Mössbauer spectra of sample $\mathrm{h}(8.4$ at $\% \mathrm{Fe})$ at $4.2 \mathrm{~K}$ without and within a longitudinal external field of $80 \mathrm{kOe}$. 
crystalline one-dimensional antiferromagnets [27]. However, the existence of spin waves in frustrated amorphous magnets is still debated [28].

The frustration implied by the combination of negative superexchange interactions and of topological disorder leads well below $T_{\mathrm{f}}$ to a new type of magnetic order (speromagnetism) : the spins are frozen in random directions and antiferromagnetic correlations extend, at the most, over a few interatomic distances [29]. Speromagnetic structure is proven at $4.2 \mathrm{~K}$ for the present glasses by investigating the magnetic polarization induced by an external field. For sample $\mathrm{h}(8.4$ at \%), application at $4.2 \mathrm{~K}$ of a field of $80 \mathrm{kOe}$ has no effect on the average linepositions while minor changes affect the relative line areas and linewidths (Fig. 10). Both effects reveal negligible moment polarization even by such large external fields in accordance with the strong negative exchange revealed by the large value of the paramagnetic Curie temperature, i.e. $\theta_{\mathrm{p}}=-115 \mathrm{~K}$ for sample $\mathrm{h}(8.4$ at $\% \mathrm{Fe})$. The slight $(5 \%)$ decrease of linewidth is attributed to the quenching of relaxation persisting at $4.2 \mathrm{~K}$ in the absence of external field. This conclusion is consistent with the temperature dependence in the absence of field, which shows between 4.2 and $1.4 \mathrm{~K}$ a slight increase of the outer line intensity (Figs. 4, 6). Also, the deduced magnetic ordering agrees with the small value of the induced magnetization (a few \% of theoretical $\mathrm{Fe}^{3+}$ saturation value) and with the absence of saturation at fields as large as $150 \mathrm{kOe}[11,12]$.

4.2 LOWER CONCENTRATION RANGe. - A quite different magnetic behaviour is observed for the lower concentration range (Figs. 2 and 3). Sample c $(3.0$ at $\%$ ) shows a quadrupole doublet down to $4.2 \mathrm{~K}$, while at the same temperature a magnetic hyperfine structure component coexists with a quadrupole doublet in samples $\mathrm{a}$ and $\mathrm{b}$ (with respectively 0.6 and 1.8 at $\%$ ). The fraction of the magnetically split component increases with decreasing iron concentration (Fig. 3). As already discussed, this concentration dependence, along with the temperature dependence observed for each sample (Fig. 2), characterize the occurrence of paramagnetic relaxation effects. The coexistence of slow- and fast relaxing $\mathrm{Fe}^{3+}$ ions reveals a non-statistical distribution of these ions within the glass matrix. The hyperfine field at $4.2 \mathrm{~K}$ corresponding to the $\pm 5 / 2$ state of the slow relaxing $\mathrm{Fe}^{3+}$ ions amounts to $520 \mathrm{kOe}$.

Application of a large longitudinal magnetic field (up to $80 \mathrm{kOe}$ ) on sample c (3.0 at \%) reveals a magnetic splitting for a fraction of the $\mathrm{Fe}^{3+}$ ions (Fig. 11). The field dependence of the outer lines (c) follows a Brillouin law $\left(S=5 / 2, \mu=5 \mu_{\mathrm{B}}\right)$, indicating that this component arises from isolated $\mathrm{Fe}^{3+}$ ions. The saturation value of $H_{\mathrm{hf}}$ equals $-530 \mathrm{kOe}$. The central part of the spectra (a) does not split and merely corresponds to the applied field. Thus, this component is attributed to antiferromagnetically

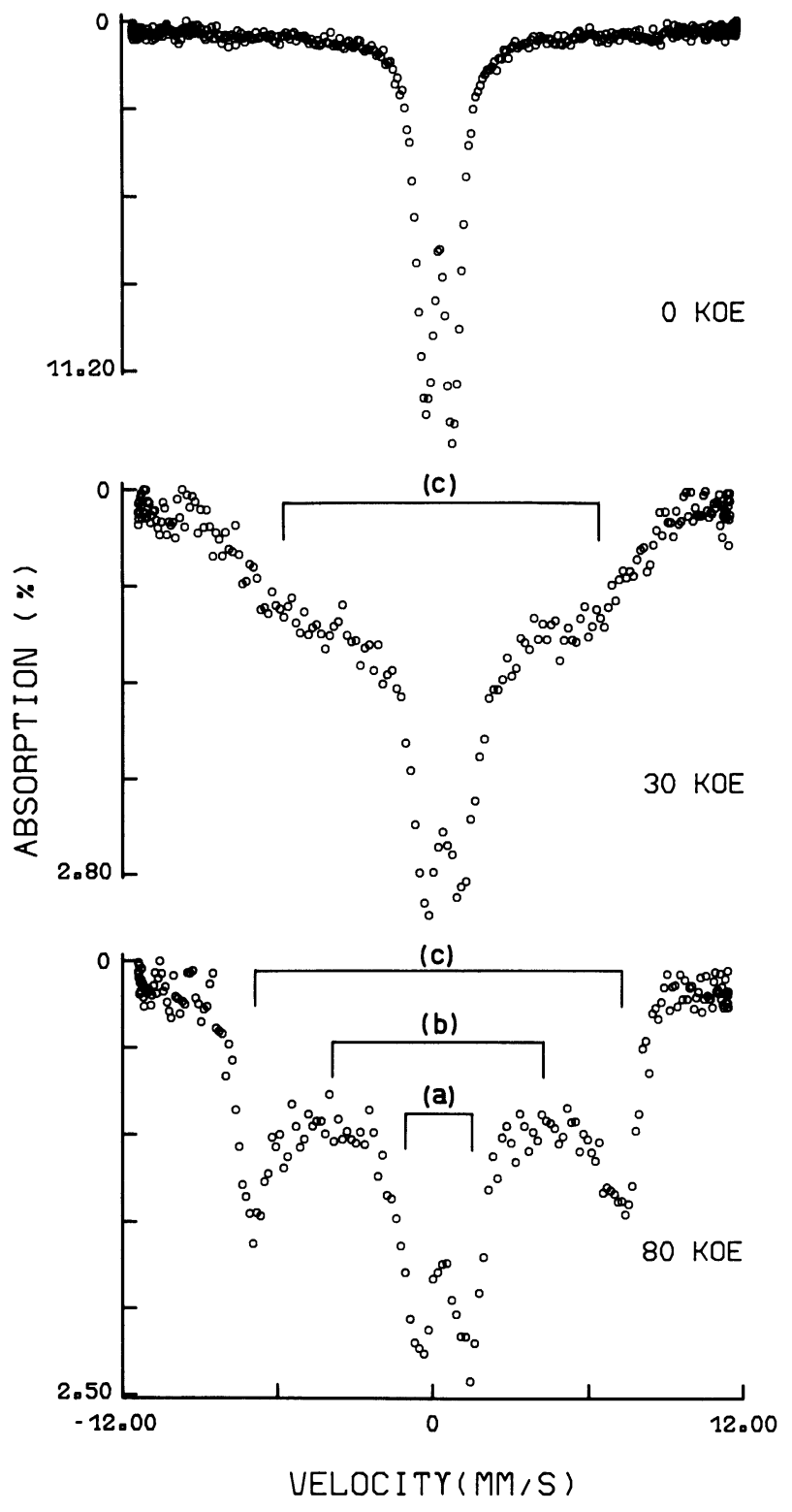

Fig. 11. - Applied field (longitudinal) dependence of the Mössbauer spectra of sample c $(3.0$ at $\% \mathrm{Fe})$ at $4.2 \mathrm{~K}$. The bar diagram refers to the three subspectra corresponding to isolated $\mathrm{Fe}^{3+}$ ions (c), antiferromagnetically coupled dimers (a) and larger iron clusters (b).

coupled dimers which as a whole behave as nonmagnetic. The lines (b), between the outer set and the central portion of the spectra, correspond to an effective field of $-250 \mathrm{kOe}$ and are tentatively assigned to antiferromagnetically coupled trimers [30]. The above discussion is consistent with the observed reduction of Curie constant for this composition $\left(C_{\mathrm{M}}=3.43 \mathrm{vs}\right.$. free ion value of 4.38$)$. The proportion of coupled clusters decreases with decreasing $\mathrm{Fe}$ concentration, with mainly isolated $\mathrm{Fe}^{3+}$ ions at $x=0.6$ at $\%$.

5. Structural properties of the ternary oxide glasses : $\mathrm{Li}_{2} \mathbf{O}-\mathrm{B}_{2} \mathrm{O}_{3}-\mathrm{Fe}_{2} \mathrm{O}_{3}$. - The primary structural infor- 
mation available from the Mössbauer data is the coordination and valence state of the iron ions. This type of information is generally obtained by comparing the measured isomer shifts (or hyperfine fields) to those established in crystalline compounds [31]. The $\delta_{\text {Is }}$ allows a straightforward attribution to high spin ferric or ferrous ions and can also generally provide their coordination. For instance, the $\delta_{\text {IS }}$ (at $77 \mathrm{~K}$ ) of 4-coordinated $\mathrm{Fe}^{3+}$ ions falls in the range from 0.26 to $0.43 \mathrm{~mm} / \mathrm{s}$ ( $v s$. iron at RT) while $\delta_{\text {IS }}$ for 6-coordinated $\mathrm{Fe}^{3+}$ ions is in the range from 0.38 to $0.63 \mathrm{~mm} / \mathrm{s}$ [32].

From the $77 \mathrm{~K}$ Mössbauer data of the present glasses (Table II), it is concluded that $\mathrm{Fe}^{3+}$ ions are present in both tetrahedral and octahedral coordinations. This is also confirmed from crystallization study [12], which initiates with the formation of $\mathrm{LiFe}_{5} \mathrm{O}_{8}$ where the $\mathrm{Fe}^{3+}$ ions present both coordinations. The 4-coordinated $\mathrm{Fe}^{3+}$ ions experience a larger electric field gradient than the 6-coordinated ones. Both the average isomer shift and quadrupole splitting of the $\mathrm{Fe}^{3+}$ ions increase with decreasing $\mathrm{Li}_{2} \mathrm{O}$ content (Tables $\mathrm{I}$ and II) as already reported by Raman et al. [33]. These authors account for this behaviour in terms of a change of coordination from tetrahedral to octahedral with decreasing $\mathrm{Li}_{2} \mathrm{O}$ content. However, this explanation is inconsistent with the present results which show that the $\mathrm{Li}_{2} \mathrm{O}$ proportion does not affect the $\mathrm{Fe}^{3+}\left(\mathrm{O}_{h}\right) / \mathrm{Fe}^{3+}\left(\mathrm{T}_{d}\right)$ ratio. Combining the two sets of data, it is suggested that the glasses including $\mathrm{Li}$ as a cation differ structurally from those with other $(\mathrm{Na}, \mathrm{K})$ alkali cations. This conclusion is supported by the monotonous decrease of average $\delta_{\text {IS }}$ as a function of $\mathrm{Li}_{2} \mathrm{O}$ proportion reported by Raman et al. [33], while for $\mathrm{Na}_{2} \mathrm{O}$ or $\mathrm{K}_{2} \mathrm{O}$ glass modifiers a sharp anomaly is observed for $\delta_{\text {IS }}$ at a specific alkali oxide concentration.

The effect of $\mathrm{Li}_{2} \mathrm{O}$ addition on the structural evolution of the borate network has been investigated in detail from ${ }^{11} \mathrm{~B}$ nuclear magnetic resonance in $\mathrm{B}_{2} \mathrm{O}_{3}-\mathrm{Li}_{2} \mathrm{O}$ glasses by Bray and his coworkers [34]. For a molar ratio $R$ of alkali oxide to boron oxide smaller than 0.5 , they observe in addition to $\mathrm{BO}_{3}$ units a growing fraction of boron atoms in tetrahedral coordination $\left(\mathrm{BO}_{4}\right.$ units) for increasing $\mathrm{Li}_{2} \mathrm{O}$ content. For $0.5 \leqslant R \leqslant 1$, i.e., the concentration range of interest here, the proportion of both symmetrical $\mathrm{BO}_{3}$ and $\mathrm{BO}_{4}$ units decreases whereas a fraction of asymmetric $\mathrm{BO}_{3}$ units (with one or two non-bridging oxygens) grows with $R$. It has been recently argued that the decrease of both $\delta_{\text {IS }}$ and the quadrupole splitting of $\mathrm{Fe}^{3+}$ ions with increasing alkali oxide content might be connected with the formation of non-bridging oxygens in the neighbourhood of these ions [35]. However, further investigations are needed to confirm such a proposal and no arguments can be inferred from the present results to support this hypothesis. It is felt that no strictly significant information can be inferred from the present results with respect to the glass former or glass modifier property of the iron atoms in the considered glasses. Such type of investigation would require a detailed investigation of the iron coordination dependence on the ratio of alkali to boron elements and on the iron concentration respectively. Moreover, the $\mathrm{B}_{2} \mathrm{O}_{3}$ glasses might not represent the best choice for such studies since the coordination geometry of boron already changes from triangular to tetrahedral in binary alkali oxide-boron oxide glasses.

A distribution of quadrupole splittings, deduced from the Lorentzian linebroadenings, is observed in all of the investigated samples. As discussed extensively previously, this is attributed to fluctuations around average values of bonding angles and distances within nearly constant structural units (octahedra and tetrahedra) [10].

Relevant information about the heterogeneity of the iron distribution within the glass host is inferred from the local magnetic data revealed by Mössbauer spectroscopy. The observation in the lower $\mathrm{Fe}$ concentration range of small magnetic clusters (dimers and trimers) coexisting with isolated $\mathrm{Fe}^{3+}$ ions agrees with earlier reports $[10,30]$ and turns out to represent a common feature for iron-based oxide glasses. According to susceptibility data (Curie constant), the $\mathrm{Fe}^{3+}$ ions occur predominantly as isolated species in the lower iron concentration glass $(0.6$ at $\%)[11,12]$. However, the inhomogeneous paramagnetic relaxation behaviour observed for this sample indicates that the $\mathrm{Fe}^{3+}$ ions are not randomly distributed in the glass matrix.

6. Conclusion - The valence and coordination of the iron ions in $\mathrm{Li}_{2} \mathrm{O}-\mathrm{B}_{2} \mathrm{O}_{3}-\mathrm{Fe}_{2} \mathrm{O}_{3}$ glasses $(\leqslant 8.4$ at $\% \mathrm{Fe}$ ) have been determined by ${ }^{57} \mathrm{Fe}$ Mössbauer spectroscopy. The $\mathrm{Fe}^{3+}$ ions occur in both tetrahedral and octahedral coordinations; the presence of $\mathrm{Fe}^{2+}$ ions, in some glasses, corresponds determinantly to equilibrium conditions in the preparation process.

The magnetic properties, ascertained from combined bulk (ac-susceptibility, magnetization) and local (Mössbauer) measurements, are determined primarily by the iron content in the glasses. At low iron concentration $(\leqslant 3$ at $\%$ ) Mössbauer studies in external fields demonstrate the coexistence of magnetic clusters on the atomic scale with isolated $\mathrm{Fe}^{3+}$ ions. At 0.6 at $\% \mathrm{Fe}$, the $\mathrm{Fe}^{3+}$ ions occur mainly as isolated ions; however, they are distributed non-statistically in the glass.

In the upper concentration range ( 3.8 to 8.4 at $\%$ ), the glasses present a mictomagnetic transition at $T_{\mathrm{f}}$ as characterized from Mössbauer and ac-susceptibility measurements. The temperature $T_{\mathrm{f}}$ increases monotonously with the iron concentration. Strong interactions among the clusters are evidenced through the frequency dependence of $T_{\mathrm{f}}$ which follows a Fulcher law. Well below $T_{\mathrm{f}}$ the spins freeze into a 
random arrangement, resulting in a speromagnetic structure. Although a temperature dependent distribution of exchange interaction or distribution of transition temperatures via chemical heterogeneities cannot be ruled out definitively from present results, it is suggested that, similar to $\mathrm{Eu}_{1-x} \mathrm{Gd}_{x} \mathrm{~S}$, the mictomagnetic transitions at $T_{\mathrm{f}}$ proceed via a progressive freezing of random fluctuations of cluster magnetization. However, one should notice that the above basic ambiguity about the actual nature of the spin glass transition affects most of the existing experimental results and affords a particularly challenging question.

Acknowledgments. - We thank C. Chaumont and J. C. Bernier for providing the samples and for communication of their dc-susceptibility and magnetization data.

\section{References}

[1] Gaskell, P. H., J. Non-Cryst. Solids 32 (1979) 207 ; J. Phys. C 12 (1979) 4337.

[2] Lines, M. E., Phys. Rev. B 20 (1979) 3729 ; ibid. B 21 (1980) 5793 ; J. Non-Cryst. Solids 46 (1981) 1.

[3] Amorphous Magnetism I, ed. H. O. Hooper and A. M. de Graff (Plenum Press, New York) 1973.

[4] Amorphous Magnetism II, ed. R. A. Levy and R. Hasegawa (Plenum Press, New York) 1977.

[5] BeCK, P. A., in Liquid and Amorphous Metals, ed. E. Lüscher, H. Coufal (Sijthoff and Noordhoff, Alphen van den Rijn, Holland) 1980 , p. 545 ; Prog. Mat. Sci. 23 (1978) 1.

[6] Mydosh, J. A., J. Magn. Magn. Mater. 7 (1978) 237.

[7] Maletta, H., Felsch, W., Phys. Rev. B 20 (1979) 1245.

[8] Litterst, F. J., Friedt, J. M., Tholence, J. L., Holtzberg, F., J. Phys. C 15 (1982) 1049.

[9] Verhelst, R. A., Kline, R. W., De GrafF, A. M., HoOPer, H. O., Phys. Rev. B 11 (1975) 4427.

[10] Bonnenfant, A., Friedt, J. M., Maurer, M., SanCHEZ, J. P., J. Physique 43 (1982) 1475.

[11] Chaumont, C., Derory, A., Bernier, J. C., Mat. Res. Bull. 15 (1980) 771

[12] Chaumont, C., Bernier, J. C., to be published in the Proceedings of the " $5 \mathrm{e}$ Congrès International sur la Physique des Solides non cristallins" Montpellier, juillet 1982, to appear in J. Physique Colloq.

[13] The collaboration of J. L. Tholence for performing the ac-susceptibility measurements is gratefully acknowledged.

[14] Hang Nam OK, Morrish, A. H., Phys. Rev. B 22 (1980) 4215.

[15] Morgownik, A. F. J., Mydosh, J. A., Wenger, L. E., J. Appl. Phys. 53 (1982) 2211.

[16] Ferré, J., Pommier, J., Renard, J. P., Knorr, K., J. Phys. C 13 (1980) 3697.
[17] Mulder, C. A. M., Van Duyneveldt, A. J., Mydosh, J. A., Phys. Rev. B 23 (1981) 1384.

[18] Morup, S., Dumesic, J. A., Topsoe, H., in Applications of Mössbauer Spectroscopy, ed. R. L. Cohen (Academic Press, New York) 1980, Vol. 2, p. 1.

[19] Dattagupta, S., Blume, M., Phys. Rev. B 10 (1974) 4540.

[20] Manykin, E. A., Onishchenko, E. V., Sov. Phys. Solid State 18 (1976) 1870.

[21] Tholence, J. L., Tournier, R., J. Physique Colloq. 35 (1974) C4-229.

[22] Tholence, J. L., Solid State Commun. 35 (1980) 113.

[23] Meert, A. T., Wenger, L. E., J. Magn. Magn. Mater. 23 (1981) 165.

[24] Maletta, H., J. Magn. Magn. Mater. 24 (1981) 179.

[25] Shtrikman, S., Wohlfarth, E. P., Phys. Lett. 85A (1981) 467.

[26] Varret, F., Henry, M., Revue Phys. Appl. 15 (1980) 1057.

[27] Gupta, G. P., Dickson, D. P. E., Johnson, C. E., J. Phys. C 11 (1978) 215.

[28] Villain, J., J. Magn. Magn. Mat. 15-18 (1980) 105.

[29] Coey, J. M. D., J. Appl. Phys. 49 (1978) 1646.

[30] Moon, D. W., Aitken, J. M., McCrone, R. K., Cieloszyk, G. S., Phys. Chem. Glasses 16 (1975) 91.

[31] Greenwood, N. N., GibB, T. C., Mössbauer spectroscopy (Chapman and Hall, London) 1971.

[32] Coey, J. M. D., J. Physique Colloq. 35 (1974) C6-89; Atomic Energy Rev. 18 (1981) 1.

[33] Raman, T., Rao, G. N., Chakravorty, D., J. NonCryst. Solids 29 (1978) 85.

[34] Yun, Y. H., BraY, P. J., J. Non-Cryst. Solids 44 (1981) 227.

[35] Nishida, T., Takashima, Y., J. Non-Cryst. Solids 37 (1980) 37. 